\title{
53rd Symposium of International Society for Clinical Electrophysiology of Vision (ISCEV)
}

Dear Guests,

Documenta Ophthalmologica, the official journal of the International Society for Clinical Electrophysiology of Vision (ISCEV), also publishes an online supplement of the abstracts of ISCEV's annual symposium. The 53rd Symposium of ISCEV takes place from June 24 to June 27, 2015, in Ljubljana, Slovenia. Abstracts were co-edited by the Scientific Committee, led by Scott Brodie and helped by Karen Holopigian, Mary Johnson, Mitchell Brigell, Anne Moskowitz and Jonathan Lyons, and the Slovenian group led by Jelka Brecelj and helped by Maja Šuštar, Martina Jarc-Vidmar and Manca Tekavčič-Pompe. The final volumes were carefully technically edited by Mr. Tone Žakelj from the University Institute for Clinical Neurophysiology, University Medical Centre Ljubljana. We conceptualized the programme this year a little differently, as the 53rd ISCEV meeting joined in part with the 12th Congress of the European
Society for Neuroophthalmology (EUNOS). The first day's programme of ISCEV and the last day's programme of EUNOS are joined to bring a blend of both disciplines that are interrelated, yet independent. The idea to join these two meetings was enthusiastically embraced by both societies, and a joint social event at Ljubljana castle will allow us to meet each other in person to foster new contacts. We are glad that both societies decided to come to Ljubljana and are grateful for this sign of appreciation of Slovenian visual electrophysiology and neuroophthalmology. Our gratitude is extended to all who have contributed to this meeting, especially to all the distinguished speakers who accepted our invitation. We sincerely hope that our hospitality, culture and nature will provide nice memories of your visit to Slovenia for a long time.

Marko Hawlina and Jelka Brecelj, Chairs, Organizing Committee 53rd ISCEV Symposium. 